\title{
Effects of pre-operative transcatheter arterial chemoembolization for resectable hepatocellular carcinoma: Implication of circulating cancer cells by detection of $\alpha$-fetoprotein mRNA
}

\author{
MASAHIRO MURAKAMI ${ }^{1}$, HIROAKI NAGANO $^{1}$, SHOGO KOBAYASHI $^{1}$, HIROSHI WADA $^{1}$, \\ MASATO NAKAMURA ${ }^{1,3}$, SHIGERU MARUBASHI ${ }^{1}$, HIDETOSHI EGUCHI ${ }^{1}$, YUTAKA TAKEDA ${ }^{1}$, \\ MASAHIRO TANEMURA ${ }^{1}$, KOJI UMESHITA ${ }^{2}$, YUICHIRO DOKI ${ }^{1}$ and MASAKI MORI ${ }^{1}$ \\ Departments of ${ }^{1}$ Surgery, and ${ }^{2}$ Health Science, Graduate School of Medicine, \\ Osaka University, Osaka; ${ }^{3}$ Aizawa Hospital, Nagano, Japan
}

Received January 11, 2010; Accepted March 11, 2010

DOI: 10.3892/etm_00000076

\begin{abstract}
Transcatheter arterial chemoembolization (TACE) is useful for the treatment of multiple hepatocellular carcinomas (HCCs). Pre-operative TACE is used to reduce recurrence caused by peri- and post-operative spread of cancer cells; however, the efficacy is controversial. In this study, we evaluated the efficacy of pre-operative TACE for HCC and the implication of circulating cancer cells, retrospectively. We analyzed 495 patients with HCC who had undergone hepatectomy between 1980 and 2006, including 252 patients (50.9\%) who received pre-operative TACE. The median follow-up period was 49.9 months. We compared the survival of TACE and non-TACE groups and also performed subgroup analysis. $\alpha$-fetoprotein (AFP) mRNA was quantified to represent circulating cancer cells. Pre-operative TACE prolonged disease-free survival after hepatectomy in patients with HCCs greater than $5 \mathrm{~cm}$ (5-year disease-free survival of the pre-operative TACE and no-TACE groups was 37.3 vs. $14.8 \%, \mathrm{p}<0.05)$. Patients with tumors showing $70 \%$ or greater necrosis had a significantly more favorable survival, and those with complete necrosis were all AFP mRNA-negative. The survival of the AFP mRNA-positive patients was worse than that of the AFP mRNA-negative
\end{abstract}

Correspondence to: Dr Hiroaki Nagano, Department of Surgery, Graduate School of Medicine, Osaka University, 2-2 Yamadaoka E-2, Suita, 565-0871, Osaka, Japan

E-mail: hnagano@gesurg.med.osaka-u.ac.jp

Abbreviations: AFP mRNA, $\alpha$-fetoprotein messenger RNA; CT, computed tomography; GAPDH, glyceraldehydes-3-phosphate dehydrogenase; HCC, hepatocellular carcinoma; PIVKA-II, protein induced by vitamin $\mathrm{K}$ antigen II; qRT-PCT, quantitative reverse transcriptase-polymerase chain reaction; TACE, transcatheter arterial chemoembolization; DFS, disease-free survival

Key words: hepatocellular carcinoma, preoperative transarterial chemoembolization, hepatectomy, circulating cancer cells, $\alpha$-fetoprotein messenger RNA patients. Pre-operative TACE may be beneficial for patients with tumors larger than $5 \mathrm{~cm}$, and AFP mRNA quantification may be useful for the prediction of survival after surgery in TACE-treated patients.

\section{Introduction}

Hepatocellular carcinoma (HCC) is one of the most common solid neoplasms worldwide, and the prognosis of patients is often poor (1). Although hepatectomy or transplantation provides better results for local control of HCC than other therapies, survival has not been satisfactory, particularly for large tumors, since both intrahepatic and extrahepatic recurrences often occur after hepatectomy even in patients who undergo a curative resection. Hematologic spread or the presence of micrometastases is thought to be the major cause of early recurrence after liver resection. Several investigators have tried to detect the presence of circulating cancer cells hematologically (2-4). Our group previously described the use of quantitative reverse transcriptase-polymerase chain reaction (qRT-PCR) to detect $\alpha$-fetoprotein (AFP) mRNA as a marker of circulating cancer cells during liver resection (5-8).

Transcatheter arterial chemoembolization (TACE) has been used widely in patients with multiple HCCs. This procedure involves injection of ionized oil and chemotherapeutic agents into the tumor-feeding artery followed by particulate embolization. Several investigators, including some clinical trials, have used this technique as neoadjuvant therapy for resectable $\mathrm{HCC}$, with the hope of minimizing post-operative recurrence and prolonging survival after hepatectomy (9-29). The efficacy of TACE, however, is still controversial, with some investigators suggesting that pre-operative TACE may be useful in several selected groups (9-19). For these reasons, we hypothesized that pre-operative TACE may regulate the spread of cancer cells during liver resection.

In this retrospective study, we evaluated the effects of TACE applied before hepatectomy for resectable HCC on survival and analyzed a subgroup of patients who underwent pre-operative TACE. In addition, we used qRT-PCR to measure the amount of AFP mRNA after TACE and analyzed 
Table I. Clinicopathological characteristics of the pre-operative TACE and non-TACE groups.

\begin{tabular}{lccr}
\hline Variable & Pre-operative TACE $(\mathrm{n}=252)$ & Non-TACE $(\mathrm{n}=243)$ & P-value \\
\hline Age $($ years $)$ & $60.9 \pm 8.4$ & $62.2 \pm 8.8$ & 0.107 \\
Gender (male/female) & $208 / 44$ & $191 / 52$ & 0.258 \\
HBs-Ag (+) & 108 & 96 & 0.404 \\
HCV-Ab (+) & 105 & 134 & 0.200 \\
Child-Pugh grade (A/B) & $217 / 35$ & $207 / 36$ & 0.404 \\
CLIP score (0/1-2/3-6) & $118 / 113 / 21$ & $125 / 106 / 12$ & 0.201 \\
Serum AFP (>5 ng/ml) & 78 & 72 & 0.845 \\
Serum PIVKA-II (>40 mAU/l) & 101 & 112 & 0.464 \\
Tumor size (cm) & $4.4 \pm 3.3$ & $4.0 \pm 6.7$ & 0.455 \\
Multiple tumors & 86 & 65 & 0.084 \\
Portal vein invasion (+) & 17 & 16 & 0.951 \\
Intrahepatic metastasis $(+)$ & 74 & 46 & $<0.010$ \\
TNM stage (I/II/III/IV-A) & $47 / 135 / 55 / 15$ & $53 / 130 / 41 / 19$ & 0.465 \\
\hline
\end{tabular}

TACE, transcatheter arterial embolization; AFP, $\alpha$-fetoprotein; PIVKA-II, protein induced by vitamin K antigen II. Data are expressed as the mean $\pm \mathrm{SD}$

the relationship with survival after liver resection in order to investigate the efficacy of TACE in the control of circulating cancer cells in the peripheral blood.

\section{Patients and methods}

Patients. Between October 1980 and December 2006, 713 patients underwent hepatectomy for pathologically confirmed HCC at our institution. Among these patients, 495 underwent curative resection and were eligible for evaluation in this study. Patients who had the following factors were excluded: re-operative cases, patients with extrahepatic metastasis or lymph node metastasis, mixed HCC, pre-operative neoadjuvant chemotherapy other than TACE and non-curative resection. The surgical procedure was selected according to the status of liver function and cancer spread. All patients received follow-up with abdominal computed tomography (CT) and serum AFP measurements every 3 months in the first 2 years and every 6 months thereafter. The treatment for recurrence of HCC was determined by the recurrence pattern and the localization, and the liver function and general condition. The median follow-up period was 50 months (range 0-249 months).

After discussing the mode and advantage or disadvantage of this treatment with the patients and their relatives, they were given the choice to receive or not to receive pre-operative TACE. Among the 495 patients, 252 (50.9\%) underwent TACE before operation (pre-operative TACE group), while 243 cases (49.1\%) underwent liver resection without pre-operative TACE (non-TACE group). There was a significant difference between the TACE and non-TACE group in terms of pre-operative intrahepatic metastasis [74 (29.4\%) and 46 (18.9\%) patients, respectively, $\mathrm{p}<0.01$ ], but no significant difference was noted among other baseline characteristics including age, gender, viral infection background, Child-Pugh grade, positive ratio of tumor markers for HCC, tumor size and number, portal vein invasion and TNM stage (Table I).
The retrospective study protocol was approved by the Human Ethics Review Committee of Osaka University, and a signed consent was obtained from each patient.

TACE method. Using the Seldinger's Technique (30), a catheter was inserted selectively into the right or left hepatic artery or the tumor-feeding artery if identified. The chemotherapeutic regimens were based mainly on epirubicin (Farmorubicin ${ }^{\circledR}$ ) doxorubicin hydrochloride $\left(\right.$ Adriacin $\left.^{\circledR}\right)$ or mitomycin C (Mitomycin $^{\circledR}$ ) (all from Kyowa Hakko, Tokyo) according to the volume of the tumor and liver function. Most patients also underwent embolization with iodized oil (Lipiodol ${ }^{\circledR}$ ) (Guerbet, Tokyo) and gelatin-sponge particles. The mean and median intervals between pre-operative TACE and hepatectomy were 2.3 and 1.7 months, respectively (range 0.2-11.3 months). After TACE, there were no serious complications requiring operative, endoscopic or radiologic intervention under general anesthesia (> grade IIIb in the Classification of Surgical Complications) (31).

Detection of AFP mRNA. From 1999, peripheral blood samples $(16 \mathrm{ml})$ were obtained pre-operatively from each HCC patient. Quantitative RT-PCR was used for the detection of AFP mRNA in peripheral blood as described previously (6). The level of AFP mRNA in the blood was expressed relative to that of the mRNA of glyceraldehyde-3-phosphate dehydrogenase (GAPDH). The lower limit of detection of the AFP mRNA by qRT-PCR was $1.0 \times 10^{-8}$; values above this level were designated as positive as described previously $(5,6)$.

Statistical methods. All data are presented as the mean \pm standard deviation. Differences in clinicopathologic parameters between the groups were compared by the Student's t-test for continuous variables or the Chi-square test for others. Overall and disease-free survivals were calculated with the KaplanMeier method, and differences in survival between groups 
A

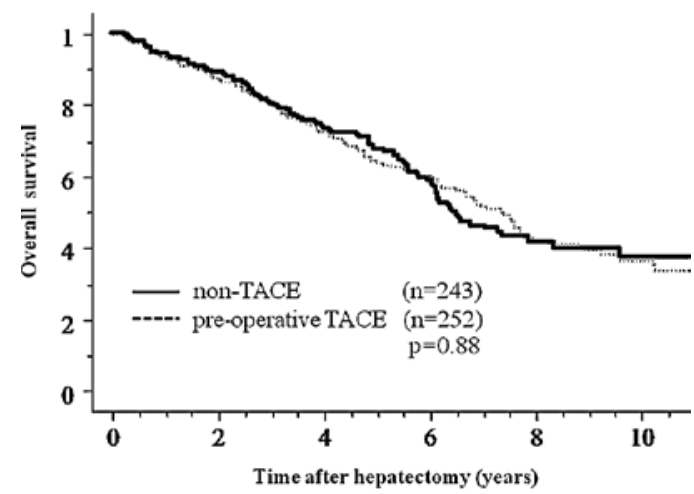

B

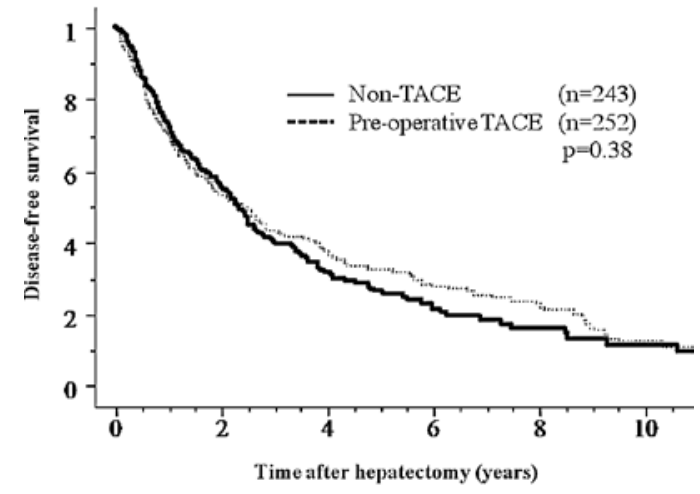

Figure 1. Overall survival (A) and disease-free survival (B) curves after hepatectomy for pre-operative TACE and non-TACE groups. No significant differences were observed between the two groups (overall survival, $p=0.88$; disease-free survival, $\mathrm{p}=0.38$ ).

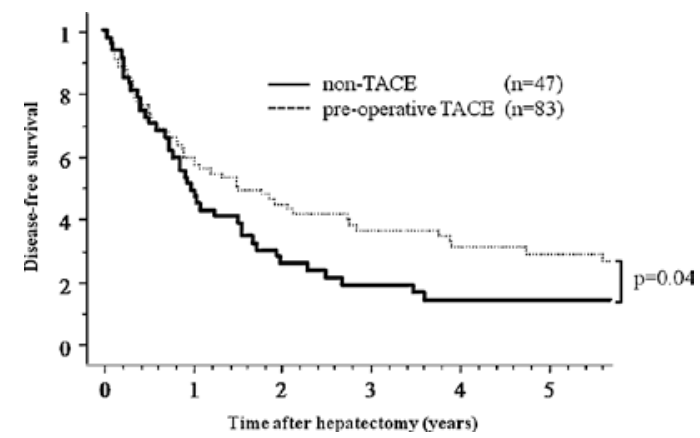

Figure 2. Disease-free survival curves after hepatectomy for patients who received or did not receive TACE pre-operatively and who had HCC tumors measuring $\geq 5 \mathrm{~cm}$ in diameter. The pre-operative TACE group showed a more favorable outcome than the non-TACE group $(\mathrm{p}=0.04)$.

were compared using the log-rank test. A value $\mathrm{p}<0.05$ was considered statistically significant. The statistical software used was StatView J-5.0 software (SAS, Cary, NC).

\section{Results}

Effect of pre-operative TACE on survival after hepatectomy. No significant differences were observed between the pre-operative TACE group and the non-TACE group regarding overall survival and disease-free survival after hepatectomy (Fig. 1). In order to elucidate the clinical effects of pre-operative TACE, subgroup analysis was performed by dividing patients according to several clinicopathologic factors including age,
Table II. Subclass analysis of overall and disease-free survival.

\begin{tabular}{lcc}
\hline Variable & Overall survival & Disease-free survival \\
\hline $\begin{array}{l}\text { Age } \\
<60\end{array}$ & 0.805 & 0.559 \\
$\geq 60$ & 0.973 & 0.631 \\
Gender & & \\
Male & 0.579 & 0.225 \\
Female & 0.367 & 0.976 \\
HBs-Ag & & \\
$(-)$ & 0.722 & 0.884 \\
$(+)$ & 0.899 & 0.176 \\
HCV-Ab & & \\
$(-)$ & 0.691 & 0.903 \\
$(+)$ & 0.703 & 0.993
\end{tabular}

Child-Pugh grade

$\begin{array}{lll}\text { A } & 0.710 & 0.250 \\ \text { B } & 0.395 & 0.758 \\ \text { CLIP score } & & \\ 0 & 0.506 & 0.226 \\ 1-2 & 0.699 & 0.916 \\ 3-6 & 0.829 & 0.252\end{array}$

AFP

$\begin{array}{lll}<5 \mathrm{ng} / \mathrm{ml} & 0.112 & 0.994 \\ \geq 5 \mathrm{ng} / \mathrm{ml} & 0.358 & 0.421\end{array}$

PIVKA-II

$\begin{array}{lll}<40 \mathrm{mAU} / 1 & 0.633 & 0.353 \\ & 0.587 & 0.458\end{array}$

$\begin{array}{lll}\geq 40 \mathrm{mAU} / \mathrm{l} & 0.587 & 0.458\end{array}$

Tumor size

$<5 \mathrm{~cm} \quad 0.630$

0.682

$\geq 5 \mathrm{~cm} \quad 0.702$

0.040

Tumor number

$\begin{array}{lll}\text { Single } & 0.334 & 0.176 \\ \text { Multiple } & 0.711 & 0.761\end{array}$

Portal vein invasion
$(-)$
0.873
0.421
$(+)$
0.520
0.344

Intrahepatic metastasis

0.550

0.239

$(+)$

0.524

0.257

TNM stage

$\begin{array}{lll}\text { I } & 0.523 & 0.925 \\ \text { II } & 0.771 & 0.625 \\ \text { III } & 0.645 & 0.326 \\ \text { IV-A } & 0.191 & 0.260\end{array}$

gender, background of viral infection, Child-Pugh grade, tumor markers for $\mathrm{HCC}$, tumor size and number, portal vein invasion, intrahepatic metastasis and TNM stage (Table II). In the subgroup analyses, only the pre-operative TACE group with tumor size $\geq 5 \mathrm{~cm}$ in diameter showed a significant benefit as reflected by an increase in disease-free survival 
A

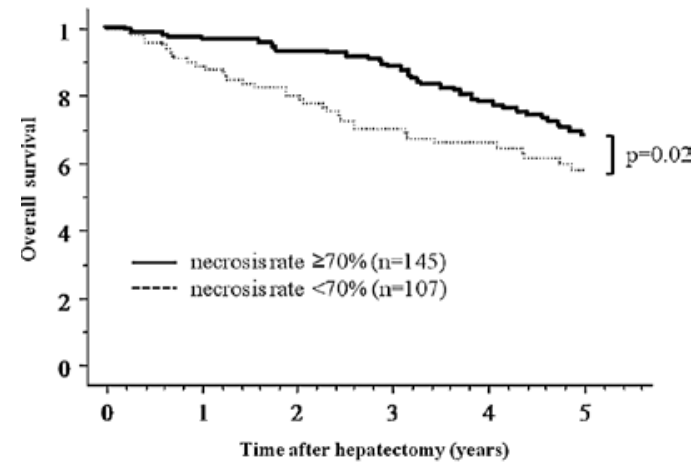

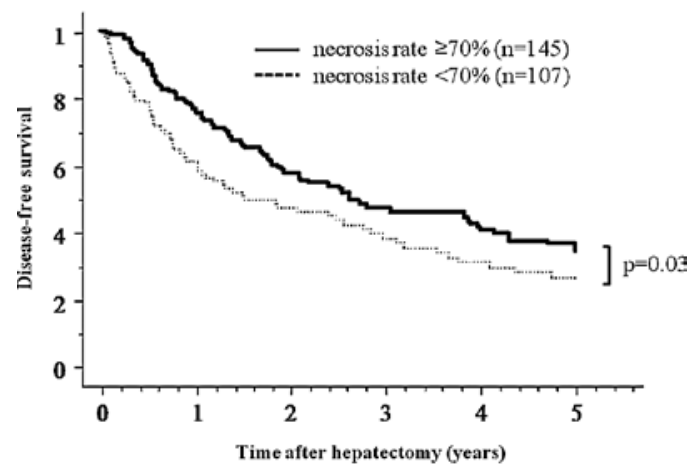

Figure 3. (A) Overall survival curve for the pre-operative TACE group according to the necrosis rate induced by TACE. (B) The 5-year overall and diseasefree survival for necrosis rate $\geq 70 \%$ was better than that for necrosis rate $<70 \%(\mathrm{p}=0.02)$.

Table III. Clinicopathological characteristics of the pre-operative TACE and non-TACE groups with tumor size $\geq 5 \mathrm{~cm}$ in diameter.

\begin{tabular}{lccr}
\hline Variable & Pre-operative TACE $(\mathrm{n}=83)$ & Non-TACE $(\mathrm{n}=47)$ & P-value \\
\hline Age $($ years $)$ & $60.3 \pm 8.5$ & $61.9 \pm 9.2$ & 0.319 \\
Gender (male/female) & $71 / 12$ & $37 / 10$ & 0.304 \\
HBs-Ag (+) & 43 & 23 & 0.556 \\
HCV-Ab (+) & 28 & 19 & 0.575 \\
Child-Pugh grade (A/B) & $71 / 12$ & $42 / 5$ & 0.594 \\
CLIP score (0/1-2/3-6) & $32 / 44 / 7$ & $15 / 26 / 6$ & 0.632 \\
Serum AFP $(>5$ ng/ml) & 49 & 29 & 0.376 \\
Serum PIVKA-II $(>40$ mAU/l) & 52 & 28 & 0.270 \\
Tumor size (cm) & $7.9 \pm 3.5$ & $9.6 \pm 13.8$ & 0.281 \\
Multiple tumor & 36 & 22 & 0.585 \\
Portal vein invasion (+) & 10 & 8 & 0.414 \\
Intrahepatic metastasis $(+)$ & 34 & 21 & 0.640 \\
TNM stage $(\mathrm{I} / \mathrm{II} / \mathrm{III} / \mathrm{IV}-\mathrm{A})$ & $0 / 49 / 25 / 9$ & $0 / 25 / 12 / 10$ & 0.356 \\
\hline
\end{tabular}

TACE, transcatheter arterial embolization; AFP, $\alpha$-fetoprotein; PIVKA-II, protein induced by vitamin K antigen II. Data are expressed as the mean $\pm \mathrm{SD}$.

after hepatectomy compared to the non-TACE group $(\mathrm{p}=0.04)$ (Fig. 2), but no benefit in overall survival was noted $(\mathrm{p}=0.70)$. There was no difference in the clinicopathologic background between patients of the two groups with tumors $\geq 5 \mathrm{~cm}$ in diameter (Table III). Additionally, to evaluate the influence of tumor size, we divided patients into groups according to $1 \mathrm{~cm}$ differences in tumor diameter and analysed each group regarding survival; there were no significant benefits between groups except for neoplasms $\geq 5 \mathrm{~cm}$. Analysis of sites of recurrence showed that 134 and 36 patients experienced intrahepatic and extrahepatic recurrence in the pre-operative TACE group, and 153 and 25 patients in the non-TACE group $(\mathrm{p}=0.09)$.

Effect of the rate of tumor cell necrosis on survival. To determine the prognostic importance of the extent of necrosis of the tumor after TACE, patients treated with pre-operative TACE were divided into two groups according to the degree of tumor necrosis, and survival was calculated. The results of the Kaplan-Meier method showed that the overall and disease-free survivals over 5 years after hepatectomy for patients with tumors showing $\geq 70 \%$ necrosis $(\mathrm{n}=145)$ were superior to those with $<70 \%$ necrosis $(\mathrm{n}=107)$. The $1-, 3$ - and 5 -year overall survival rates were $97.1,88.2$ and $68.2 \%$ for the $\geq 70 \%$ necrosis group, and 89.1, 70.3 and $58.1 \%$ for the $<70 \%$ necrosis group, respectively ( $\mathrm{p}=0.02$ ) (Fig. 3). The 1-, 3- and 5 -year disease-free survival rates were 75.5, 46.9 and $36.5 \%$ for the $\geq 70 \%$ necrosis group, and $60.8,38.5$ and $27.0 \%$ for the $<70 \%$ necrosis group, respectively $(\mathrm{p}=0.03)$. Analysis of recurrence sites showed that 82 and 12 patients experienced intrahepatic and extrahepatic recurrence in the $\geq 70 \%$ tumor necrosis group, and 52 and 24 patients in the $<70 \%$ tumor necrosis group $(\mathrm{p}<0.01)$.

Patients with HCCs $\geq 5 \mathrm{~cm}$ exhibited a benefit of preoperative TACE for disease-free survival in our study. By contrast, the necrosis rate was another prognostic factor in overall and disease-free survival. Therefore, we performed another analysis for patients with HCCs $\geq 5 \mathrm{~cm}$ and $\geq 70 \%$ necrosis. A survival benefit was noted in both overall and disease-free survival for patients bearing $\geq 5 \mathrm{~cm}$ HCCs in the $\geq 70 \%$ necrosis group; the 5 -year overall and disease-free 
Table IV. Studies on pre-operative TACE for HCC.

\begin{tabular}{|c|c|c|c|c|c|}
\hline Author (Refs.) & $\begin{array}{c}\text { No. of } \\
\text { patients* }\end{array}$ & Tumor factor & $\begin{array}{c}\% \text { Overall survival } \\
\text { TACE vs. control } \\
\text { (years) }\end{array}$ & $\begin{array}{c}\text { \% Disease-free survival } \\
\text { TACE vs. control } \\
\text { (years) }\end{array}$ & Result \\
\hline \multicolumn{6}{|l|}{ Clinical trials } \\
\hline Wu et al (20) & $24: 48$ & Ts $\geq 10 \mathrm{~cm}$ & 32 vs. $60(5)$ & 40 vs. 50 (3) & Harmful \\
\hline Yamasaki et al (21) & $50: 47$ & $2 \leq$ Ts $\leq 5 \mathrm{~cm}$ & 63 vs. $62(5)$ & 39 vs. 31 (5) & NS \\
\hline Zhou et al (22) & $52: 56$ & $\mathrm{Ts} \geq 5 \mathrm{~cm}$ & 31 vs. $21(5)$ & 13 vs. 9 (5) & NS \\
\hline Peng et al (9) & $51: 53$ & $\mathrm{Vp}$ & 21 vs. $8.5(5)$ & NA & Effective \\
\hline Zhong et al (11) & $59: 59$ & Stage IIIA & 23 vs. $18(5)$ & 9 vs. $2(5)$ & Effective \\
\hline \multicolumn{6}{|l|}{ Retrospective studies } \\
\hline Imaoka et al (17) & $37: 52$ & $\mathrm{Ts}<10 \mathrm{~cm}$ & NA & 72 vs. $54(2)$ & Effective \\
\hline Monden et al (23) & $71: 21$ & & 63 vs. 62 (3) & NA & NS \\
\hline Nagasue et al (27) & $31: 107$ & & 31 vs. $45(3)$ & NA & NS \\
\hline Adachi et al (18) & $46: 26$ & $\begin{array}{c}\mathrm{Ts} \leq 5 \mathrm{~cm}, \mathrm{Vp}(-) \\
\mathrm{Vv}(-), \mathrm{IM}(-)\end{array}$ & NA & 52 vs. 49 (3) & Effective (CN group) \\
\hline Harada et al (15) & $98: 33$ & & 78 vs. 68 (3) & 38 vs. 34 (3) & Effective (CN group) \\
\hline Uchida et al (28) & $60: 68$ & & 61 vs. 73 (3) & 57 vs. 48 (3) & Harmful \\
\hline Majno et al (14) & $49: 27$ & & 57 vs. 47 (3) & 33 vs. $22(3)$ & $\begin{array}{l}\text { Effective (downstage } \\
\text { or } \mathrm{CN} \text { group) }\end{array}$ \\
\hline Paye et al (24) & $24: 24$ & & 62 vs. 65 (3) & 32 vs. $16(3)$ & NS \\
\hline Di Carlo et al (13) & $55: 45$ & $\mathrm{Ts} \leq 5 \mathrm{~cm}$ & 70 vs. 38 (3) & 40 vs. 20 (3) & Effective \\
\hline Lu et al (12) & $\begin{array}{l}44: 76 \\
(24: 57) \\
(20: 19)\end{array}$ & $\begin{array}{c}2 \leq \text { Ts } \leq 8 \mathrm{~cm} \\
\text { Ts } \geq 8 \mathrm{~cm}\end{array}$ & $\begin{array}{l}50 \text { vs. } 52(3) \\
42 \text { vs. } 61(3) \\
53 \text { vs. } 33(3)\end{array}$ & $\begin{array}{l}32 \text { vs. } 36(3) \\
21 \text { vs. } 43(3) \\
32 \text { vs. } 11(3)\end{array}$ & $\begin{array}{c}\text { NS } \\
\text { NS } \\
\text { Effective }\end{array}$ \\
\hline Zhang et al (19) & $120: 1337$ & & NA & $\begin{array}{c}51(\mathrm{n} \geq 2) \text { vs. } 36(\mathrm{n} \geq 1) \\
\text { vs. } 21 \text { (control) }(5)\end{array}$ & Effective \\
\hline Gerunda et al (16) & $20: 17$ & $\mathrm{Ts} \leq 5 \mathrm{~cm}$ & 43 vs. 38 (5) & 57 vs. $21(5)$ & Effective (DFS) \\
\hline Sugo et al (10) & $\begin{array}{c}13: 73 \\
(58: 35) \\
(55: 38)\end{array}$ & $\begin{array}{c}\text { Stage I, II } \\
\text { Stage III, IV }\end{array}$ & $\begin{array}{l}\text { NA } \\
\text { NA } \\
\text { NA }\end{array}$ & $\begin{array}{l}46 \text { vs. } 39(3) \\
\text { NA } \\
41 \text { vs. } 21(3)\end{array}$ & $\begin{array}{c}\text { NS } \\
\text { NS } \\
\text { Effective }\end{array}$ \\
\hline Sasaki et al (25) & $109: 126$ & & 28 vs. $50(5)$ & 19 vs. $22(5)$ & Harmful \\
\hline Choi et al (26) & $120: 153$ & & NA & 51 vs. $47(5)$ & NS \\
\hline Lee et al (29) & $114: 236$ & & 47 vs. $52(5)$ & 29 vs. 36 (5) & Harmful \\
\hline
\end{tabular}

TACE, transcatheter arterial embolization; Ts, tumor size; Vp, portal vein invasion; Vv, hepatic vein invasion; IM, intrahepatic metastasis; NA, not available; $\mathrm{CN}$, complete necrosis. "Patients that received to those that did not receive TACE.

survival rates were 63.9 and $41.0 \%(n=43)$, and for patients bearing $\geq 5 \mathrm{~cm}$ HCCs in the $<70 \%$ necrosis group, 42.8 and $16.1 \%(\mathrm{n}=40)(\mathrm{p}=0.02$ and $\mathrm{p}<0.01$, respectively $)$.

Changes in AFP mRNA in peripheral blood. Among the last 123 patients for whom serum AFP mRNA was measured preoperatively, $13(11.6 \%)$ were positive. There was a significant difference between the AFP mRNA-positive and -negative groups in terms of protein induced by vitamin $\mathrm{K}$ antigen II (PIVKA-II) $(\mathrm{p}<0.05)$, but not in the other clinicopathologic parameters analyzed. Among 53 patients who underwent preoperative TACE, 5 patients were AFP mRNA-positive, and pre-operative AFP mRNA was negative in 12 patients who showed complete TACE-related necrosis, although the statistical difference was not significant $(p=0.20)$. Quantification of
AFP mRNA revealed that AFP mRNA-positive patients who received pre-operative TACE had the worst overall survival after hepatectomy compared to the AFP mRNA-negative patients. Among the pre-operative TACE group, the 5-year overall survival rates were $60.0 \%$ for the AFP mRNA-positive group $(n=5)$, and $88.8 \%$ for the AFP mRNA-negative group $(\mathrm{n}=48)$, respectively $(\mathrm{p}=0.02)$. Also, AFP mRNA-positive patients with a tumor size $\geq 5 \mathrm{~cm}$ showed similar results; the 5 -year overall survival rates were $0 \%(n=2$; each 0.4 and 1.25 years), and $83.3 \%(\mathrm{n}=20)$, respectively $(\mathrm{p}=<0.01)$.

\section{Discussion}

One of the reasons for the high recurrence rate in $\mathrm{HCC}$ is postulated to be the potential hematogenous spread of cancer 
cells pre- or intra-operatively, even if curative resection is performed. This possible phenomenon is probably due to the characteristics of HCC or the surgical manipulation during hepatectomy itself. Irrespective of the underlying etiology, it is important to control this hematogenous spread of cancer cells, and one of the purposes of pre-operative TACE is to prevent such spread and improve the outcome after curative resection.

In order to improve the survival rate after surgery for HCC, several researchers have tried pre-operative TACE; however, its clinical benefits are still controversial (Table IV) (9-29). Half of these studies including randomized controlled trials (RCTs) demonstrated effective results regarding pre-operative TACE while others did not or showed harmful results. Our results showed that pre-operative TACE prolonged the diseasefree survival in patients with HCC tumors measuring $5 \mathrm{~cm}$ or more in diameter. In these previous studies, some authors supported our results, i.e., pre-operative TACE was effective in large or stage III-IV tumors (9-12). On the other hand, two RCTs showed the opposite results $(20,22)$. However, the background of these patients differed from ours; both studies involved large tumor $(\geq 10 \mathrm{~cm})$ in hepatitis B carriers.

Subgroup analysis based on other clinicopathological factors, such as portal vein invasion, intrahepatic metastasis and TNM stage, which are considered important factors in the prognosis of HCC patients, showed that pre-operative TACE had no significant benefits to survival. Several studies have documented the poor response to TACE in patients with satellite lesions, intrahepatic recurrence or tumor thrombosis $(12,13,25,26)$. The generally poor response of patients with portal vein invasion, intrahepatic metastasis or advanced HCC to pre-operative TACE and subsequently to surgery, may be explained by the aforementioned reasons.

On the other hand, our results suggest that pre-operative TACE is beneficial for patients with HCCs $5 \mathrm{~cm}$ or more in diameter. Of these patients, the mortality rate of AFP mRNApositive patients was worse, even when they underwent pre-operative TACE. Although this finding may suggest hematological spread of cancer cells before surgery, the change in AFP mRNA levels should be analyzed before or after both pre-operative TACE and surgery, since it is doubtful whether pre-operative AFP mRNA was positive before TACE or became positive after TACE. Nonetheless, AFP mRNA may be a good prognostic marker of HCC.

The relationships between TACE-induced tumor necrosis, tumor spread and survival remain controversial (10-18,22-26). Our results showed that the 5-year overall and disease-free survival of patients with tumors showing a necrosis rate of $70 \%$ or higher was more favorable than the survival of patients with tumors showing less than $70 \%$ necrosis. In agreement with these results, the pre-operative AFP mRNA of all 12 patients who showed TACE-related complete necrosis was negative. Furthermore, the analysis of recurrence sites found that patients bearing tumors with a necrosis rate less than $70 \%$ were more likely to develop extrahepatic recurrence. Previous studies reported a higher incidence of extrahepatic metastasis in AFP mRNA-positive patients, either before or after TACE (32). These data indicate that complete necrosis induced by pre-operative TACE seems to inhibit extrahepatic metastasis and may be a suitable marker of favorable patient outcome.
Although the necrosis rate was determined through histopathological examination, some studies have evaluated the therapeutic response of TACE using modalities including dynamic CT, contrast-enhanced sonography, power Doppler sonography, dynamic MRI and angiography $(33,34)$. However, we consider it insufficient to assess the effect of TACE pre-operatively. On the other hand, although the number of samples in this study was limited, the necrosis rate in 4 of the $5(80 \%)$ AFP mRNA-positive patients who received pre-operative TACE was less than $70 \%$. These findings suggest differences in survival between patients bearing tumors with a necrosis rate equal to or greater than 70 and patients bearing tumors with less than $70 \%$ necrosis. Although further examination is required, we can anticipate the efficacy of AFP mRNA in peripheral blood for patient survival after surgery following TACE.

In conclusion, pre-operative TACE may be beneficial for patients with HCC tumors measuring more than $5 \mathrm{~cm}$ in diameter. These patients should undergo TACE before curative resection to prolong disease-free survival. However, tumor necrosis equal to or greater than $70 \%$ is necessary for more favorable survival. Our results also showed that quantification of AFP mRNA in peripheral blood after TACE is potentially useful for the prediction of $\mathrm{HCC}$ recurrence.

\section{Acknowledgements}

We thank Yukari Sugita for measuring the AFP mRNA in peripheral blood. This study was supported by a Grant-in-Aid for Cancer Research from the Ministry of Culture and Science, and the Ministry of Health and Welfare of Japan.

\section{References}

1. Poon RT, Fan ST, Tsang FH and Wong J: Locoregional therapies for hepatocellular carcinoma: a critical review from the surgeon's perspective. Ann Surg 235: 466-486, 2002.

2. Witzigmann H, Geissler F, Benedix F, et al: Prospective evaluation of circulating hepatocytes by alpha-fetoprotein messenger RNA in patients with hepatocellular carcinoma. Surgery 131: 34-43, 2002.

3. Lemoine A, Le Bricon T, Salvucci M, et al: Prospective evaluation of circulating hepatocytes by alpha-fetoprotein mRNA in humans during liver surgery. Ann Surg 226: 43-50, 1997.

4. Kamiyama T, Takahashi M, Nakagawa T, et al: AFP mRNA detected in bone marrow by real-time quantitative RT-PCR analysis predicts survival and recurrence after curative hepatectomy for hepatocellular carcinoma. Ann Surg 244: 451-463, 2006.

5. Morimoto O, Nagano H, Miyamoto A, et al: Association between recurrence of hepatocellular carcinoma and alpha-fetoprotein messenger RNA levels in peripheral blood. Surg Today 35: 1033-1041, 2005.

6. Miyamoto A, Nagano H, Sakon M, et al: Clinical application of quantitative analysis for detection of hematogenous spread of hepatocellular carcinoma by real-time PCR. Int J Oncol 18: 527-532, 2001.

7. Marubashi S, Dono K, Sugita Y, et al: Alpha-fetoprotein mRNA detection in peripheral blood for prediction of hepatocellular carcinoma recurrence after liver transplantation. Transplant Proc 38: 3640-3642, 2006.

8. Marubashi S, Dono K, Nagano H, et al: Detection of AFP mRNA-expressing cells in the peripheral blood for prediction of HCC recurrence after living donor liver transplantation. Transpl Int 20: 576-582, 2007. 
9. Peng BG, He Q, Li JP and Zhou F: Adjuvant transcatheter arterial chemoembolization improves efficacy of hepatectomy for patients with hepatocellular carcinoma and portal vein tumor thrombus. Am J Surg 198: 313-318, 2009.

10. Sugo H, Futagawa S, Beppu T, Fukasawa M and Kojima K: Role of pre-operative transcatheter arterial chemoembolization for resectable hepatocellular carcinoma: relation between postoperative course and the pattern of tumor recurrence. World J Surg 27: 1295-1299, 2003.

11. Zhong C, Guo RP, Li JQ, et al: A randomized controlled trial of hepatectomy with adjuvant transcatheter arterial chemoembolization versus hepatectomy alone for Stage III A hepatocellular carcinoma. J Cancer Res Clin Oncol 135: 1437-1445, 2009.

12. Lu CD, Peng SY, Jiang XC, Chiba $\mathrm{Y}$ and Tanigawa $\mathrm{N}$ Pre-operative transcatheter arterial chemoembolization and prognosis of patients with hepatocellular carcinomas: retrospective analysis of 120 cases. World J Surg 23: 293-300, 1999.

13. Di Carlo V, Ferrari G, Castoldi R, et al: Pre-operative chemoembolization of hepatocellular carcinoma in cirrhotic patients. Hepatogastroenterology 45: 1950-1954, 1998.

14. Majno PE, Adam R, Bismuth $\mathrm{H}$, et al: Influence of pre-operative transarterial lipiodol chemoembolization on resection and transplantation for hepatocellular carcinoma in patients with cirrhosis. Ann Surg 226: 688-703, 1997.

15. Harada T, Matsuo K, Inoue T, Tamesue $S$ and Nakamura $H$ : Is preoperative hepatic arterial chemoembolization safe and effective for hepatocellular carcinoma? Ann Surg 224: 4-9, 1996.

16. Gerunda GE, Neri D, Merenda R, et al: Role of transarterial chemoembolization before liver resection for hepatocarcinoma. Liver Transpl 6: 619-626, 2000.

17. Imaoka S, Sasaki Y, Shibata T, et al: A pre-operative chemoembolization therapy using lipiodol, cisplatin and gelatin sponge for hepatocellular carcinoma. Cancer Chemother Pharmacol 23 S126-S128, 1989.

18. Adachi E, Matsumata $T$, Nishizaki $T$, Hashimoto $H$, Tsuneyoshi M and Sugimachi K: Effects of pre-operative transcatheter hepatic arterial chemoembolization for hepatocellular carcinoma. The relationship between postoperative course and tumor necrosis. Cancer 72: 3593-3598, 1993.

19. Zhang Z, Liu Q, He J, Yang J, Yang G and Wu M: The effect of pre-operative transcatheter hepatic arterial chemoembolization on disease-free survival after hepatectomy for hepatocellular carcinoma. Cancer 89: 2606-2612, 2000.

20. Wu CC, Ho YZ, Ho WL, Wu TC, Liu TJ and P'Eng FK: Pre-operative transcatheter arterial chemoembolization for resectable large hepatocellular carcinoma: a reappraisal. $\mathrm{Br} J$ Surg 82: 122-126, 1995.

21. Yamasaki S, Hasegawa $\mathrm{H}$, Kinoshita $\mathrm{H}$, et al: A prospective randomized trial of the preventive effect of pre-operative transcatheter arterial embolization against recurrence of hepatocellular carcinoma. Jpn J Cancer Res 87: 206-211, 1996.
22. Zhou WP, Lai EC, Li AJ, et al: A prospective, randomized, controlled trial of pre-operative transarterial chemoembolization for resectable large hepatocellular carcinoma. Ann Surg 249: 195-202, 2009.

23. Monden M, Okamura J, Sakon M, et al: Significance of transcatheter chemoembolization combined with surgical resection for hepatocellular carcinomas. Cancer Chemother Pharmacol 23: S90-S95, 1989.

24. Paye F, Jagot P, Vilgrain V, Farges O, Borie D and Belghiti J: Pre-operative chemoembolization of hepatocellular carcinoma: a comparative study. Arch Surg 133: 767-772, 1998.

25. Sasaki A, Iwashita Y, Shibata K, Ohta M, Kitano S and Mori M: Pre-operative transcatheter arterial chemoembolization reduces long-term survival rate after hepatic resection for resectable hepatocellular carcinoma. Eur J Surg Oncol 32: 773-779, 2006.

26. Choi GH, Kim DH, Kang CM, et al: Is pre-operative transarterial chemoembolization needed for a resectable hepatocellular carcinoma? World J Surg 31: 2370-2377, 2007.

27. Nagasue N, Galizia G, Kohno H, et al: Adverse effects of preoperative hepatic artery chemoembolization for resectable hepatocellular carcinoma: a retrospective comparison of 138 liver resections. Surgery 106: 81-86, 1989.

28. Uchida M, Kohno H, Kubota H, et al: Role of pre-operative transcatheter arterial oily chemoembolization for resectable hepatocellular carcinoma. World J Surg 20: 326-331, 1996.

29. Lee KT, Lu YW, Wang SN, et al: The effect of pre-operative transarterial chemoembolization of resectable hepatocellular carcinoma on clinical and economic outcomes. J Surg Oncol 99: 343-350, 2009.

30. Seldinger SI: Catheter replacement of the needle in percutaneous arteriography; a new technique. Acta Radiol 39: 368-376, 1953.

31. Dindo D, Demartines $N$ and Clavien PA: Classification of surgical complications: a new proposal with evaluation in a cohort of 6336 patients and results of a survey. Ann Surg 240: 205-213, 2004

32. Gross-Goupil M, Saffroy R, Azoulay D, et al: Real-time quantification of AFP mRNA to assess hematogenous dissemination after transarterial chemoembolization of hepatocellular carcinoma. Ann Surg 238: 241-248, 2003.

33. Jang MK, Lee HC, Kim IS, et al: Role of additional angiography and chemoembolization in patients with hepatocellular carcinoma who achieved complete necrosis following transarterial chemoembolization. J Gastroenterol Hepatol 19: 1074-1080, 2004.

34. Herber S, Biesterfeld S, Franz U, et al: Correlation of multislice $\mathrm{CT}$ and histomorphology in HCC following TACE: predictors of outcome. Cardiovasc Intervent Radiol 31: 768-777, 2008. 